\title{
GCU
}

Glasgow Caledonian

University

University for the Common Good

\section{Liver mortality attributable to chronic hepatitis C virus infection in Denmark and Scotland: using spontaneous resolvers as the benchmark comparator}

Innes, Hamish; Hutchinson, Sharon J.; Obel, Niels; Christensen, Peer B.; Aspinall, Esther J.; Goldberg, David; Krarap, Henrik; McDonald, Scott A.; McLeod, Allan; Weir, Amanda; Omland, Lars. $\mathrm{H}$.

Published in:

Hepatology

DOI:

10.1002/hep.28458

Publication date:

2016

Document Version

Author accepted manuscript

Link to publication in ResearchOnline

Citation for published version (Harvard):

Innes, H, Hutchinson, SJ, Obel, N, Christensen, PB, Aspinall, EJ, Goldberg, D, Krarap, H, McDonald, SA, McLeod, A, Weir, A \& Omland, LH 2016, 'Liver mortality attributable to chronic hepatitis C virus infection in Denmark and Scotland: using spontaneous resolvers as the benchmark comparator', Hepatology, vol. 63, no. 5, pp. 1506-1516. https://doi.org/10.1002/hep.28458

\section{General rights}

Copyright and moral rights for the publications made accessible in the public portal are retained by the authors and/or other copyright owners and it is a condition of accessing publications that users recognise and abide by the legal requirements associated with these rights.

Take down policy

If you believe that this document breaches copyright please view our takedown policy at https://edshare.gcu.ac.uk/id/eprint/5179 for details of how to contact us. 


\section{TITLE}

Liver mortality attributable to chronic hepatitis C virus infection in Denmark and Scotland - using spontaneous resolvers as the benchmark comparator

AUTHOR LIST:

INNES H $^{1,2}$; HUTCHINSON SJ ${ }^{1,2}$, OBEL N $^{3}$, CHRISTENSEN PB ${ }^{4}$, ASPINALL EJ ${ }^{1,2}$, GOLDBERG D $^{1,2}$, KRARUP $^{2}$

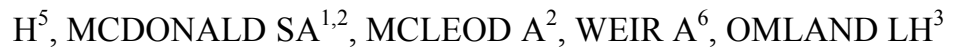

\section{AFFILIATIONS:}

1. Glasgow Caledonian University; School of Health and Life Sciences; Glasgow, UK.

2. Health Protection Scotland; Blood borne viruses and STIs; Glasgow, UK.

3. Copenhagen University Hospital; Department of Infectious Diseases; Rigshospitalet, Copenhagen, Denmark.

4. Odense University Hospital; Department of Infectious Diseases; Odense, Denmark.

5. Aalborg University Hospital, Aalborg Hospital; Section of Molecular Diagnostics, Clinical Biochemistry; Aalborg, Denmark

6. NHS; National Services Scotland; Edinburgh, UK.

DETAILS OF CORRESPONDING AUTHOR:

NAME: Mr Hamish Adam Innes

ADDRESS: School of Health and Life Sciences, Glasgow Caledonian University, Cowcaddens Rd, G4 0BA, UK, EMAIL ADDRESSS(ES): Hamish.innes@gcu.ac.uk; Hamish.innes@nhs.net TELEPHONE NUMBER(S): 0141-3001106; 0141-3313915

ELECTRONIC WORD COUNT: 5,800

NUMBER OF FULL-TEXT TABLES: 3

NUMBER OF FULL-TEXT FIGURES:1

CONTRIBUTION STATEMENT: SH, HI, PC, LO and NO initiated the study. Statistical analyses and drafting of the manuscript were carried out by LO and HI. All authors contributed to the study design, interpretation of results, and revising the manuscript. 
FUNDING STATEMENT: This work was supported, in part, by funding from the Scottish Government.

ROLE OF STUDY SPONSOR: The Scottish government had no involvement in the design of this study; in the analysis and interpretation of data; in the writing of the report; and in the decision to submit the article for publication.

COMPETING INTEREST STATEMENT: HI reports receipt of speaker fees from Gilead. SJH reports grants from Scottish Government, during the conduct of the study; personal fees from Abbvie, Gilead, Janssen, MSD, Roche, grants from Janssen, outside the submitted work. All other authors have nothing to disclose.

KEY WORDS: Epidemiology; Chronic liver disease; Chronic viral hepatitis; Alcohol; Antiviral therapy

ABBREVIATIONS AND ACRONYMS (in order of appearance):

CHC, chronic hepatitis $\mathrm{C}$; $\mathrm{HCV}$, hepatitis $\mathrm{C}$ virus; LMR, liver mortality rate; $\mathrm{LMR}_{\text {resolved }}$, Liver mortality rate (for individuals diagnosed with spontaneously resolved hepatitis $\mathrm{C}$ virus infection); $\mathrm{LMR}_{\text {chronic }}$, Liver mortality rate (for individuals diagnosed with Chronic hepatitis $\mathrm{C}$ virus infection); AF, attributable fraction; TAF, total attributable fraction; IDU, injecting drug use; AUD, alcohol use disorder; DANVIR, Danish hepatitis C virus cohort; RNA, ribonucleic acid; DNPR, Danish national patient registry; CHI, community health index; PCR, polymerase chain reaction; ICD, international classification of diseases; N.B, nota bene; HR, hazard ratio 


\section{ABSTRACT}

Liver mortality among individuals with chronic hepatitis $\mathrm{C}(\mathrm{CHC})$ infection is common, but the relative contribution of $\mathrm{CHC}$ per se versus adverse health behaviours is uncertain. We explored data on spontaneous resolvers of hepatitis $\mathrm{C}$ virus (HCV) as a benchmark group, to uncover the independent contribution of $\mathrm{CHC}$ on liver mortality. Using national HCV diagnosis and mortality registers from Denmark and Scotland, we calculated the liver mortality rate (LMR) for persons diagnosed with $\mathrm{CHC}$ infection ( $\left.\mathrm{LMR}_{\text {chronic }}\right)$ and spontaneously resolved infection ( $\left.\mathrm{LMR}_{\text {resolved }}\right)$, according to subgroups defined by: age; gender; and drug use. Through these mortality rates we determined subgroup-specific attributable fractions $(\mathrm{AFs})$, defined as $\left(\mathrm{LMR}_{\text {chronic }}-\mathrm{LMR}_{\text {resolved }}\right) / \mathrm{LMR}_{\text {chronic. }}$, and then calculated the Total Attributable Fraction (TAF) as a weighted average of these AFs. Thus, the TAF represents the overall fraction (where $0.00=$ not attributable at all; and 1.00=entirely attributable) of liver mortality attributable to $\mathrm{CHC}$ in the diagnosed population. Our cohort comprised 7005, and 21729 persons diagnosed with HCV antibodies in Denmark and Scotland, respectively. The mean follow up duration was 6.3-6.9 years. The TAF increased stepwise with age. It was lowest for death occurring at $<45$ years of age (0.21 in Denmark; 0.26 in Scotland); higher for death occurring 45-59years ( 0.69 in Denmark; 0.69 in Scotland) and highest for death at 60+years (0.92 in Denmark; 0.75 in Scotland). Overall, the TAF was 0.66 (95\%:0.55-0.78) in Denmark and 0.55 (95\%CI: 0.44-0.66) in Scotland. Conclusion: In Denmark and Scotland, the majority of liver death in the CHC-diagnosed population can be attributed to CHC- nevertheless, an appreciable fraction cannot, cautioning that liver mortality in this population is a compound problem that can be reduced but not solved through antiviral therapy alone. 


\section{INTRODUCTION}

Persons with Chronic Hepatitis C (CHC) infection exhibit rates of liver mortality that are between 17 and 36 times greater than the general population[1-6]. A prerequisite to an effective public-health response, is a complete understanding of the factors driving this phenomenon. Although $\mathrm{CHC}$ is an established cause of liver failure and liver cancer, we cannot assume that all liver deaths occurring in the $\mathrm{CHC}$ infected population are de-facto attributable to CHC. To judge the CHC contribution, we need to uncover the benchmark mortality rate; in other words, the rate of liver mortality that this population would exhibit in the absence of $\mathrm{CHC}$. This is a challenging task; CHC infection is inextricably linked to high rates of: injecting drug use (IDU)[7-9], alcohol use disorders (AUDs) [9-14], psychiatric comorbidities $[9,11]$ and polysubstance abuse [15]. Epidemiologically, it is hard to disentangle liver mortality attributable to $\mathrm{CHC}$, from liver mortality that might have occurred anyway given competing risk factors.

A potentially misprized benchmark group, overlooked until now, are spontaneous resolvers. The natural history of infection is such that, upon exposure to the virus, three-quarters of individuals develop persisting chronic infection that is clearable only through antiviral treatment [16]. But the remaining quarter resolve the infection spontaneously (i.e. of their own accord) within a matter of weeks to months [17]. Resolvers, by virtue of being exposed to HCV at all, are likely to be broadly similar to their chronic counterparts in terms of lifestyle exposures. In this sense then, resolvers may serve as a useful yardstick from which to assess the independent contribution of CHC. With these thoughts in mind, a joint research initiative between Denmark and Scotland was established. To our knowledge, we are the only two countries in the developed world: (i) with a national HCV diagnosis database capable of distinguishing persons diagnosed with HCV antibodies according to their chronic versus resolved infection status, and (ii) where those databases are linked routinely to subsequent mortality data. Using these unique data, our aim was to examine the extent to which liver mortality in persons with $\mathrm{CHC}$, is indeed a CHC-related phenomenon. 


\section{METHODS}

\section{STUDY DESIGN AND SETTING:}

We performed a record linkage analysis utilising $\mathrm{HCV}$ diagnosis, hospitalisation and mortality registers in two distinct settings - Denmark and Scotland. Both are Northern European countries with 5.5 million inhabitants. The estimated prevalence of CHC infection is $\sim 0.4 \%$ in Denmark [18] (equivalent to $\sim 17,000$ individuals) and $\sim 0.8 \%$ in Scotland [19] ( $\sim 39,000$ individuals). In both settings, the principal transmission route is IDU $[7,20]$. In Denmark, $\sim 0.5 \%$ of persons living with $\mathrm{CHC}$ receive antiviral therapy each year [21], whereas in Scotland, treatment uptake is higher at 2.5-3\% [19]. Official population statistics on alcohol use and related sequalae suggest historically higher consumption levels in Denmark than in Scotland; albeit, differences have diminished over the last decade (see eFig.1).

\section{DATA SOURCES:}

Denmark: HCV infected patients were identified from the Danish HCV diagnosis database (known as DANVIR), comprising all persons tested for HCV in 14 of the 18 laboratories that perform such testing in Denmark [6]. DANVIR data include results and dates of HCV antibody tests (from 1991 onward) and HCV RNA tests (from 1995 onward). Data on the vital status of all Danish citizens, including date of death or emigration, is stored by the Civil Registration System [22]. The Danish National Registry of Causes of Death contains information on date and causes of death on all deceased Danish citizens [23]. The Danish National Patient Registry (DNPR), established in 1977, collects information on all non-psychiatric hospital admissions in Denmark, and since 1995, outpatient and emergency department visits moreover. Data linkage between DANVIR and: (i) the Civil Registration System; (ii) the Danish National Registry of Causes of Death; and (iii) the DNPR, was performed through deterministic matching of the unique 10-digit civil registration number assigned to all individuals in Denmark [22].

Scotland: HCV infected individuals were identified through the Scottish HCV diagnosis database, which records all new anti-HCV positive diagnoses in Scotland from 1991 onwards [1]. Scotland also holds a national database for: (i) all general and acute inpatient/day case hospital admissions (known as the SMR-01 database); (ii) all mental health inpatient/day case admissions (known as the SMR-04 database); and (iii) all deaths [24]. The HCV diagnosis database was linked to these three registries through a two-step process. Using the full set of patient identifiers held on the HCV diagnosis (forename initial, surname soundex, date of birth, gender, postcode sector), an intermediary linkage to the Community Health Index (CHI) database was performed to obtain the "CHI number" (step 1). The CHI number is a 
unique individual-specific number allocated to every person upon registration with a general practitioner in Scotland; it functions as a master index for linkage between population registries in Scotland and is equivalent to the aforementioned Danish civil-registration number. Knowledge of the CHI number therefore enabled retrieval of each HCV diagnosed patient's records from the SMR-01, SMR-04, and mortality databases (step 2). These linkages were performed by Information Services Division Scotland, after approval from National Services Scotland Privacy Advisory Committee.

\section{INCLUSION AND EXCLUSION CRITERIA:}

The inclusion criteria was receipt of a first-time diagnosis for HCV antibodies from the year comprehensive PCR testing was introduced (1995 in Denmark and 1996 in Scotland) until the year diagnosis data were complete to (2007 in Denmark and 2012 in Scotland). A total of 11,977 Danish persons, and 30,049 Scottish persons met these initial inclusion criteria. After applying appropriate exclusions (mainly for missing data on HCV infection status; and for Scotland, also for not linking to the CHI database, see eFig.2), our final analysis featured 7,005 and 21,729 individuals from Denmark and Scotland, respectively.

\section{EXPOSURE VARIABLES}

The primary exposure variable was chronic versus spontaneous resolved HCV infection inferred from the first determinate HCV RNA test conducted following or simultaneous to the diagnosis of HCV antibodies. Specifically, a first test with a positive HCV RNA result was taken to indicate chronic infection, whilst a first test with a negative result was taken to indicate spontaneous resolution. In Scotland, trained data entry staff with access to full PCR test history apply this definition manually to all patient records. In contrast, for Denmark where all RNA tests are recorded and stored within DANVIR itself, this definition was applied electronically. We also characterised individuals in terms of IDU history. For Denmark, IDU was defined as inclusion in the Registry of Drug Abusers Undergoing Treatment and/or a record of one or more diagnoses suggesting IDU in the DNRP (Appendix A). For Scotland, a history of IDU was based on risk information disclosed by the patient at the time of the HCV test.

\section{OUTCOME VARIABLE}

Liver mortality was the primary outcome. This was defined using the underlying (i.e. primary) cause of death, specified by the followingICD-9 and ICD-10 codes: primary liver cancer (ICD-10 C22; ICD-9 155); alcoholic liver disease (ICD- 
10 K70;ICD-9 571.0-571.3); non-alcoholic liver disease (ICD-10 K71-77; ICD-9 570, 571.4-571.9, 572-573); viral hepatitis (ICD-10 B15-19; ICD-9 070); and sequelae of viral hepatitis (ICD-10 B94.2; R18; I850; ICD-9 456.0, 789.5).

\section{STATISTICAL ANALYSIS:}

To avoid breaching patient confidentiality safeguards, Danish and Scottish linkage data were analysed separately, by different authors (LO and HI), but according to a single standardised protocol. The main analysis was to determine the fraction of liver death in the $\mathrm{CHC}$ diagnosed population that is attributable to $\mathrm{CHC}$ (i.e. that would not have occurred if $\mathrm{CHC}$ had not been present). We further carried out an auxiliary analysis, and a one-way sensitivity analysis to support interpretation of the main analysis - as follows:

\section{(i) MAIN ANALYSIS: FRACTION OF LIVER DEATH ATTRIBUTABLE TO CHC}

For subgroups defined by current age group ( $<45$ years; $45-59$ years; and $60+$ years), gender (male versus female) and IDU history (known history versus no known history), we determined the liver mortality rate (LMR) for patients with chronic $\left(\mathrm{LMR}_{\text {chronic }}\right)$ and resolved $\left(\mathrm{LMR}_{\text {resolved }}\right) \mathrm{HCV}$ infection. The LMR for each subgroup was calculated by dividing the aggregate number of liver deaths, by the aggregate time at risk. For each individual, time at risk (expressed in person-years) began 180 days after HCV diagnosis (as is standard [1,2, 4-6]), and was censored either at occurrence of non-liver mortality, or at the date national mortality cdata was complete until (31 Dec 2009 in Denmark and 31 Dec 2013 in Scotland). We calculated the attributable fraction (AF) for each subgroup, defined as (LMR chronic $_{-}$ $\mathrm{LMR}_{\text {resolved }} / \mathrm{LMR}_{\text {chronic. }}$ Where $\mathrm{LMR}_{\text {resolved }}$ exceeded $\mathrm{LMR}_{\text {chronic }}$, we took the $\mathrm{AF}$ in that subgroup to be zero. AFs indicates the fraction of liver death attributable to $\mathrm{CHC}$ (i.e $0.00=$ not attributable at all; $0.5=$ equally attributable and non-attributable; $1.00=$ entirely attributable). The indicative number of liver deaths attributable to CHC was determined by multiplying the subgroup-specific AF by the number of liver deaths occurring with $\mathrm{CHC}$ infection in that same subgroup. To derive the total attributable fraction (TAF), we divided the indicative total number of liver deaths attributable to $\mathrm{CHC}$ by the total liver deaths occurring with $\mathrm{CHC}$ infection. The TAF thus, is effectively a weighted average of subgroup-specific AFs; and it is interpretable as an estimate of the fraction of liver mortality attributable to $\mathrm{CHC}$ in the diagnosed population. We used a bootstrapping approach to quantify imprecision in all our estimates. From our original cohort, we sampled with replacement to generate 10,000 bootstrap samples, each with the same number of observations as our original sample. We then repeated the above calculations for each bootstrap sample and use the $2.5^{\text {th }}$ and $97.5^{\text {th }}$ percentile in the resulting distribution to indicate the range of values consistent with our data. 

STATUS

We used Cox regression to determine the association between HCV infection status, and the time to first hospitalisation for a suite of admissions that reflect adverse health behaviours. As per our main analysis, we commenced follow-up 180 days after HCV diagnosis, and censored follow-up for mortality or for reaching the date that national hospitalisation data were complete until (31 Dec 2009 for Denmark; 31 Dec 2013 for Scotland). Three events were considered: 1) hospitalisation for an acute instance of drug intoxication; 2) hospitalisation for an acute instance of alcohol intoxication; and 3) hospitalisation for injury incurred through violence (although N.B, violence-related injury could not be assessed as a behavioural outcome in Denmark because this outcome is recorded in a separate registry that we did not have access to for this study [25]).ICD codes were used to define all events; see eTable 1 . We calculated the hazard ratio for each event, according to chronic infection versus spontaneous resolved infection, after adjustment for age group, gender and known history of IDU.

\section{(iii) SENSITIVITY ANALYSIS: ACCOUNTING FOR THE IMPACT OF ANTIVIRAL THERAPY}

Data on commencement of antiviral therapy is available in Scotland through a national HCV clinical database (described previously elsewhere: [26]). To gauge the influence of treatment on our principal conclusions, we repeated our main analysis, but this time, further censored follow-up at the date of treatment initiation (if the treatment episode in question, gave rise to attainment of SVR by April 2013).To note, the same sensitivity analysis was not performed in Denmark because linkage to the Danish clinical database (known as DANHEP), had not been conducted at the time of this analysis. 


\section{RESULTS:}

\section{DESCRIPTION OF COHORT:}

This analysis included 7,005 persons diagnosed with HCV antibodies in Denmark and 21,729 likewise persons from Scotland. Individuals in the Danish cohort, on average, were older than those in Scotland (mean age at diagnosis: 39.7 years in Denmark, versus 35.3 years in Scotland). In both settings, males outnumbered females ( 2:1 ratio), and a similar proportion reported a history of IDU $(50-60 \%)$. The fraction of individuals with resolved HCV infection versus chronic infection was higher in Denmark (37.6\%) than in Scotland (20.3\%). Consistently in both settings, resolvers were younger than those with chronic infection (on average, by 1.3-1.5 years), and were more commonly female; see Table 1.

\section{FOLLOW-UP TIME AND LIVER MORTALITY:}

The total duration of follow-up in Denmark was 46,134 person-years; equating to a median per patient observation of 6.34 years (see eTable 2). Over this observation period, 1206 individuals died, and 247 (20.5\%) of these deaths were liver-related (equating to a crude rate of 53.5 liver deaths per 10,000 person-years). In Scotland, total follow-up was 162,607 person-years; equating to a median of 6.93 years per patient. Over this duration, 2898 individuals died, with $729(25.2 \%)$ of these deaths being liver-related (crude rate:44.8 liver deaths per 10,000 person-years). In both settings, the type of liver death differed according to the HCV infection status of the decedent; see eFig.3. Most deaths among resolvers were due to alcoholic liver disease (i.e. in $>2 / 3^{\text {rds }}$ of instances), with a minimal contribution from liver cancer $(<6 \%)$. A different picture was apparent for those with chronic infection; alcoholic liver disease was less frequently indicated (in $<50 \%$ of deaths), whilst more than a fifth of liver mortality was attributed to hepatocellular carcinoma $(21.5-21.6 \%)$.

\section{MAIN ANALYSIS: FRACTION OF LIVER DEATH ATTRIBUTABLE TO CHC INFECTION}

The TAF was 0.66 (95\%:0.57-0.79) in Denmark and 0.55 (95\%CI: 0.44-0.66) in Scotland- but it varied according to the age at death (see Fig.1). The TAF was low for death occurring at $<45$ years of age; 0.21 (95\% CI: $0.11-0.63$ ) in Denmark and 0.26 (95\% CI: 0.07-0.47) in Scotland. The TAF was moderate/high for death occurring at 45-59 years of age; 0.69 (95\% CI: 0.52-0.82) in Denmark and 0.69 (95\% CI: 0.53-0.83) in Scotland. The TAF was highest for deaths at 60+years; 0.92 (95\% CI: 0.76-1.00) in Denmark and 0.75 (95\% CI: 0.49-0.95) in Scotland. 
AUXILIARY ANALYSIS: ADVERSE HEALTH BEHAVIOURS ACCORDING TO HCV INFECTION STATUS

$\mathrm{CHC}$ infection status (relative to spontaneous resolution) was not associated with a decreased risk of hospitalisation for adverse health behaviours after adjustment for age, gender and IDU history. There was some indication to the contrary however; In Denmark, CHC infection was associated with a significantly increased risk of hospitalisation drug intoxication (adjusted hazard ratio: $1.25,95 \% \mathrm{CI}: 1.06-1.49$ ); see Table 3.

\section{SENSITIVITY ANALYSIS: ACCOUNTING FOR THE IMPACT OF ANTIVIRAL THERAPY}

In Scotland, during the course of follow-up, 5059 individuals with CHC were treated with antiviral therapy and, 2436 attained SVR. We note that 94 spontaneous resolvers were also listed as having received a course of treatment during follow-up - we discuss this observation in our limitations section. When censoring follow-up time at SVR attainment, the TAF increased minimally to 0.59 (95\% CI: 0.48-0.68); see eFig 4. 


\section{DISCUSSION}

\section{PRINCIPAL FINDINGS:}

Rates of liver mortality are high among persons with CHC [1-6]. An effective public-health response to this phenomenon must reflect the causes behind these excess deaths. In this study, we use spontaneous resolvers as a benchmark group, to judge the independent contribution of CHC. Our findings indicate that in Scotland, $55 \%$ (95\% CI: 44-66) of liver death among CHC-infected individuals can be attributed to the $\mathrm{CHC}$ exposure. In Denmark, this fraction is higher at $66 \%$ ( $95 \%$ CI: $55-78)$. On the one hand, these results support the consensus view - that the majority of liver death in this population is attributable to the $\mathrm{CHC}$ exposure. At the same time, they also show that a not insignificant portion of liver mortality appears to occur independently of infection; there are two immediate corollaries of this. Firstly, although attempts to curtail liver mortality in this population rest mainly on the provision of antiviral therapy, antivirals alone may not be sufficient to eradicate the liver mortality problem. Secondly, if a baseline risk of liver disease among persons who acquire $\mathrm{HCV}$ exists, then we must ensure that this is fairly incorporated into modelling work. Existing cost-effectiveness [27-30], population forecasting [31-33], and patient prognosis models [34] tend to assume negligible disease progression in the absence of chronic infection; this assumption will likely bias results in favour of treatment and may give rise to inflated drug costs.

\section{VALIDITY OF USING SPONTANEOUS RESOLVERS AS A BENCHMARK GROUP}

Using spontaneous resolvers as a control group to gauge the independent contribution of $\mathrm{CHC}$ is a novel idea.Resolvers, by virtue of having been exposed to $\mathrm{HCV}$ at all, are likely to be broadly similar to their chronic counterparts in terms of adverse health behaviours (behaviours that are otherwise difficult to measure precisely[35.36] but which may influence liver disease progression appreciably).This assumption of similarity betweeen chronics and resolvers in terms of adverse health behaviours is supported by studies examining the determinants of spontaneous resolution [37-40]. We further performed an auxillary analysis to assess the ongoing risk of hospitalisation for acute alcohol intoxication, acute drug intoxication and hospitalisation for violence-related injury (i.e.admissions that reflect ongoing adverse health behaviors). We found similar admission risks according to infection status with the exception of a small increased risk of drug intoxication in Danish chronics versus Danish resolvers (HR 1.25; 95\% CI: 1.06-1.49). However a limitation of this auxiliary analysis is that it only considers the relationship between infection status and extreme health behaviours. In other words, the results may not generalise to moderately adverse- but harmful nonetheless - health behaviours. Spontaneous resolvers differ from chronically infected persons demographically (are more commonly younger and of 
female gender [17]), and genetically (in terms of single nucleotide polymorphisms in the vicinity of the IL28B gene [41]). Our analyses are adjusted for age and gender, but not for any genetic differences between these two groups that may govern immune system response. This is an important limitation because it might undervalue the risk that CHC poses; recent studies have shown that among individuals with $\mathrm{CHC}$, polymorphisms favouring spontaneous resolution may be associated with hepatic decompensation [42]. It is possible that these polymorphisms could hasten liver disease progression from other aetiologies [43], meaning that paradoxically, individuals who spontaneously resolve HCV may be more susceptible (in a genetic sense) to liver disease, than those who progress to chronic infection. Nevertheless, the picture is very preliminary- the potential for bias here should be reviewed as new data emerges. A further implicit assumption of this analysis is that the duration for which spontaneous resolvers harbour viral RNA (median of 16.6 weeks [17]) is sufficiently short to preclude the virus causing any significant liver damage. Very occasionally, spontaneous resolution occurs much later [44], and in these instances, the potential for HCV-induced liver damage will be greater.

\section{FURTHER LIMITATIONS AND CAVEATS}

Our definition of spontaneous resolution is based on the very first PCR test result conducted after or at the time of antibody detection. This should offer a robust indication of chronic versus resolved infection given the established serological timeline of infection [45]. However, this definition has two caveats. First some individuals will have gone on clear their chronic infection through antiviral therapy during the course of follow-up. This switch from chronic to cleared chronic is not accounted for in our base case analysis, For two reasons though, this is unlikely to impact our results: (A) at the population level, the impact of antiviral therapy on liver mortality is known to have been minimal, owing in part to poor response rates and low uptake [5]; and (B) in a sensitivity analysis where we excluded all persons known to have attained an SVR in Scotland, the TAF increased only marginally (by $<5 \%$; see eFig.4). Although, the same analysis was not performed for Denmark, we would expect an even slighter change here given lower treatment uptake rates, relative to Scotland. The second caveat is that some of our spontaneous resolvers will have been reinfected during follow-up and will have then developed chronicity through that re-infection event. When conducting our sensitivity analysis, we noticed that 94 (2\%) Scottish resolvers had been treated with antiviral therapy; these cases will reflect such instances of reinfection. This misclassification of resolver status is a limitation of our analysis; nevertheless, it will apply to a small fraction of cases only. Regarding the generalisability of these data: whilst we calculated TAFs 
for two distinct North European countries and observed broadly similar results, we would not expect our findings to hold for all settings. In particular, we would anticipate a higher TAF overall in countries with an older infected population than Denmark and Scotland (and equally a lower TAF in countries with a younger infected population). Further our TAFs are unlikely to generalise to settings where HCV transmission is not associated with adverse health behaviours (in the main, low and some middle income countries where transmission is driven by nonsocomial routes as opposed to injecting drug use). Another limitation is that $25-40 \%$ of diagnosis records were excluded from our final samples (mainly due to insufficient identifiers and missing chronic infection status) - we cannot rule out the introduction of selection bias into our results as a result of these exclusions. A further potential bias to note is that a physician may be more inclined to attribute a death to liver disease if the deceased had $\mathrm{CHC}$ infection as opposed to spontaneously resolved infection - if this is the case, then our TAFs will be biased towards one. We should further make clear that this analysis only examines the impact of $\mathrm{CHC}$ on liver sequalea and does not address the impact of CHC on extrahepatic outcomes and pyschosocial manifestations. Finally, we did not use a consistent approach to determine injecting drug use history. In Denmark, IDU status was determined via a registry of drug abusers undergoing treatment, whereas in Scotland, IDU status is based on risk information disclosed to the physician at the time of the hepatitis $\mathrm{C}$ test. It is possible that the Danish definition (i.e. appearance on a drug abuse treatment register) will select out a more persistent subset of drug users that have been repeatedly exposed to HCV, and hence have a higher chance of chronicity. This might explain why an association between injecting drug use and chronic infection was observed for Denmark but not for Scotland (see Table 1).

\section{CONSISTENCY WITH PREVIOUS WORK:}

Our analysis suggests that a significant portion of liver mortality among $\mathrm{CHC}$ infected persons occurs independently of $\mathrm{CHC}$ infection. Previous work in resource-rich settings is in support of this, and points towards the non-CHCattributable death being a reflection of adverse health behaviours (AUDs in particular); as follows:

1. HCV infection is associated with a singular lifestyle profile, distinct from that of the general population $[3,7-$ $15]$.

2. AUDs in particular are highly prevalent among persons with $\mathrm{CHC}$ [9-14] which are in turn strongly associated with liver mortality [46]. 
3. More than a third of Scottish CHC patients attending treatment services with liver cirrhosis, have reached this state as a direct consequence of heavy alcohol use [26]. Further, between 15 and $52 \%$ of liver deaths in this population are indicated directly, via the cause of death, to be a primary consequence of alcohol use. [5]. Indeed in this analysis, alcoholic liver disease was listed as the primary cause of death for $45 \%$ and $48 \%$ of liver deaths among CHC infected persons in Scotland and Denmark, respectively (see eFig.3).Thus, it is already known that that many instances of liver cirrhosis and liver mortality are attributable to alcohol use - but that is not to say that alcohol was the exclusive cause and that $\mathrm{CHC}$ did not contribute in a "necessary but insufficient" way). In this respect our results lend a distinct advancement, insofar as they indicate an appreciable fraction of liver death would still have occured in the absence of CHC.

4. When HCV is introduced into cohorts with a stable lifestyle profile, rates of liver disease remain relatively low after 2-3 decades of infection [47-50].

5. Elevated mortality rates are also apparent in the siblings of HCV infected persons. These high rates mostly reflect an excess number of unnatural and substance abuse-related deaths. An excess number of liver deaths, albeit, was not observed [51, 52].

\section{SUMMARY}

Most instances of liver mortality among $\mathrm{CHC}$ infected persons can be attributed to $\mathrm{CHC}$ - all the same, an appreciable fraction of liver death appears to be independent of this exposure. This suggests that antiviral therapy will only be a partial solution to the problem of wayward liver mortality in this population. A full solution should entail more emphasis on tackling adverse health behaviours and the circumstances that give rise to them. Recent data highlights that behavioural interventions might be effective in the HCV infected population [53]; but this historically has been (and so far still is) a neglected territory of research. 


\section{REFERENCES}

1. McDonald SA, Hutchinson SJ, Bird SM, et al. A population-based record linkage study of mortality in hepatitis C-diagnosed persons with or without HIV coinfection in Scotland. Stat Methods Med Res 2009;18(3):271-83.

2. Amin J, Law MG, Bartlett M, Kaldor JM, Dore GJ. Causes of death after diagnosis of hepatitis B or hepatitis C infection: a large community-based linkage study. Lancet 2006;368(9539):938-45.

3. El-Kamary SS, Jhaveri R, Shardell MD. All-cause, liver-related, and non-liver-related mortality among HCVinfected individuals in the general US population. Clin Infect Dis 2011;53(2):150-7.

4. Duberg A-S, Törner A, Davidsdóttir L, et al. Cause of death in individuals with chronic HBV and/or HCV infection, a nationwide community-based register study. J Viral Hepat 2008;15(7):538-50.

5. Aspinall E, Amin J, Goldberg DJ, Grebely J, Hutchinson SJ. Trends in mortality after diagnosis of hepatitis C virus infection: an international comparison and implications for monitoring the population impact of treatment. $\mathrm{J}$ Hepatol 2015; 62(2):269-77

6. Omland LH, Jepsen $\mathrm{P}$, Krarup $\mathrm{H}$, et al. Increased mortality among persons infected with hepatitis $\mathrm{C}$ virus. Clin Gastroenterol Hepatol 2011;9(1):71-8.

7. McDonald SA, Hutchinson SJ, Schnier C, McLeod A, Goldberg DJ. Estimating the number of injecting drug users in Scotland's HCV-diagnosed population using capture-recapture methods. Epidemiol Infect 2014;142(1):200-7.

8. Nelson PK, Mathers BM, Cowie B, et al. Global epidemiology of hepatitis B and hepatitis C in people who inject drugs: results of systematic reviews. Lancet 2011;378(9791):571-83.

9. Boscarino JA, Lu M, Moorman AC, et al. Predictors of poor mental and physical health status among patients with chronic hepatitis C infection: The chronic hepatitis cohort study (CHeCS). Hepatology 2015;61(3):802-11.

10. Campbell JV, Hagan H, Latka MH, et al. High prevalence of alcohol use among hepatitis $\mathrm{C}$ virus antibody positive injection drug users in three US cities. Drug Alcohol Depend 2006;81(3):259-65.

11. Lehman CL, Cheung RC. Depression, anxiety, post-traumatic stress, and alcohol-related problems among veterans with chronic hepatitis C. Am J Gastroenterol 2002;97(10):2640-6.

12. Le Marchand C, Evans J, Page K, Davidson PJ, Hahn JA. Hazardous alcohol consumption among young adult IDU and its association with high risk behaviors. Drug Alcohol Depend 2013;127(1-3):143-9.

13. Gyarmathy VA, Neaigus A. The association between social marginalisation and the injecting of alcohol amongst IDUs in Budapest, Hungary. Int J Drug Policy 2011;22(5):393-7.

14. Ryder N, Cullen W, Barry J, Bury G, Keenan E, Smyth BP. Prevalence of problem alcohol use among patients attending primary care for methadone treatment. BMC Fam Pract 2009;10:42.

15. Riley DE, Liu L, Cohen B, Robinson S, Groessl EJ, Ho SB. Characteristics and impact of methamphetamine use in patients with chronic hepatitis C. J Addict Med 2014;8(1):25-32.

16. Micallef JM, Kaldor JM, Dore GJ. Spontaneous viral clearance following acute hepatitis C infection: a systematic review of longitudinal studies. J Viral Hepat 2006;13(1):34-41.

17. Grebely J, Page K, Sacks-Davis R, et al. The effects of female sex, viral genotype, and IL28B genotype on spontaneous clearance of acute hepatitis C virus infection. Hepatology 2014;59(1):109-20.

18. Christensen PB, Hay G, Jepsen P, et al. Hepatitis C prevalence in Denmark -an estimate based on multiple national registers. BMC Infect Dis 2012;12:178. 
19. Health Protection Agency. Hepatitis C in the UK: 2012 report [Internet]. [cited 2014 Aug20];Available from: http://www.hpa.org.uk/webw/HPAweb\&HPAwebStandard/HPAweb_C/1317135237627

20. National board of Health. Guide to the prevention of viral hepatitis - June 2002 (In Danish) [Internet]. [cited 2014 Nov 25];Available from: http://sundhedsstyrelsen.dk/publ/publ2002/hepatitis/html/index.htm

21. Bruggmann P, Berg T, Øvrehus ALH, et al. Historical epidemiology of hepatitis C virus (HCV) in selected countries. J Viral Hepat 2014;21 Suppl 1:5-33.

22. Schmidt M, Pedersen L, Sørensen HT. The Danish Civil Registration System as a tool in epidemiology. Eur J Epidemiol 2014; 29(8):541-9.

23. Juel K, Helweg-Larsen K. The Danish registers of causes of death. Dan Med Bull 1999;46(4):354-7.

24. Scottish National Health Databases. SMR-01: http://www.adls.ac.uk/nhs-scotland/general-acute-inpatient-daycase-smr01/?detail ; SMR-04: http://www.adls.ac.uk/nhs-scotland/smr04-mental-health-inpatient-and-day-casedataset/?detail ; CHI database: http://www.scot-ship.ac.uk/overview.html ; All accessed April 2014.

25. Engberg AW, Penninga EI, Teasdale TW. [Nordic accident classification system used in the Danish National Hospital Registration System to register causes of severe traumatic brain injury]. Ugeskr Laeger 2007;169(45):3856-60.

26. Innes HA, Hutchinson SJ, Barclay S, et al. Quantifying the fraction of cirrhosis attributable to alcohol among chronic hepatitis C virus patients: implications for treatment cost-effectiveness. Hepatology 2013;57(2):451-60.

27. Martin NK, Vickerman P, Miners A, et al. Cost-effectiveness of hepatitis C virus antiviral treatment for injection drug user populations. Hepatology 2012;55(1):49-57.

28. Rein DB, Smith BD, Wittenborn JS, et al. The cost-effectiveness of birth-cohort screening for hepatitis C antibody in U.S. primary care settings. Ann Intern Med 2012;156(4):263-70.

29. Grieve R, Roberts J, Wright M, et al. Cost effectiveness of interferon alpha or peginterferon alpha with ribavirin for histologically mild chronic hepatitis C. Gut 2006;55(9):1332-8.

30. Wright M, Grieve R, Roberts J, Main J, Thomas HC, UK Mild Hepatitis C Trial Investigators. Health benefits of antiviral therapy for mild chronic hepatitis $\mathrm{C}$ : randomised controlled trial and economic evaluation. Health Technol Assess 2006;10(21):1-113, iii.

31. Davis GL, Alter MJ, El-Serag H, Poynard T, Jennings LW. Aging of hepatitis C virus (HCV)-infected persons in the United States: a multiple cohort model of HCV prevalence and disease progression. Gastroenterology 2010;138(2):513-21, 521.e1-6.

32. Hutchinson SJ, Bird SM, Goldberg DJ. Modeling the current and future disease burden of hepatitis C among injection drug users in Scotland. Hepatology 2005;42(3):711-23.

33. Rein DB, Wittenborn JS, Weinbaum CM, Sabin M, Smith BD, Lesesne SB. Forecasting the morbidity and mortality associated with prevalent cases of pre-cirrhotic chronic hepatitis C in the United States. Dig Liver Dis 2011;43(1):66-72.

34. Innes H, Goldberg D, Dusheiko G, et al. Patient-important benefits of clearing the hepatitis $\mathrm{C}$ virus through treatment: a simulation model. J Hepatol 2014;60(6):1118-26.

35. Heeb J-L, Gmel G. Measuring alcohol consumption: a comparison of graduated frequency, quantity frequency, and weekly recall diary methods in a general population survey. Addict Behav 2005;30(3):403-13.

36. Boniface S, Shelton N. How is alcohol consumption affected if we account for under-reporting? A hypothetical scenario. Eur J Public Health 2013;23(6):1076-81. 
37. Shah DP, Grimes CZ, Brown E, Hwang L-Y. Demographics, socio-behavioral factors, and drug use patterns: what matters in spontaneous HCV clearance? J Med

38. Page K, Hahn JA, Evans J, et al. Acute hepatitis C virus infection in young adult injection drug users: a prospective study of incident infection, resolution, and reinfection. J Infect Dis 2009;200(8):1216-26.

39. Piasecki BA, Lewis JD, Reddy KR, et al. Influence of alcohol use, race, and viral coinfections on spontaneous HCV clearance in a US veteran population. Hepatology Virol 2012;84(2):235-41. 2004;40(4):892-9.

40. Grebley J, Raffa JD, Lai C, Krajden M, Conway B, Tyndall MW. Factors associated with spontaneous clearance of hepatitis c virus among illict drug users. Can J Gastroenterol. 2007;21:447-51.

41. Duggal P, Thio CL, Wojcik GL, et al. Genome-wide association study of spontaneous resolution of hepatitis C virus infection: data from multiple cohorts. Ann Intern Med 2013;158(4):235-45.

42. Noureddin M, Wright EC, Alter HJ, et al. Association of IL28B genotype with fibrosis progression and clinical outcomes in patients with chronic hepatitis C: a longitudinal analysis. Hepatology 2013;58(5):1548-57.

43. Petta $\mathrm{S}$, Grimaudo $\mathrm{S}$, Cammà $\mathrm{C}$, et al. IL28B and PNPLA3 polymorphisms affect histological liver damage in patients with non-alcoholic fatty liver disease. J Hepatol 2012;56(6):1356-62.

44. Stenkvist J, Nyström J, Falconer K, Sönnerborg A, Weiland O. Occasional spontaneous clearance of chronic hepatitis C virus in HIV-infected individuals. J Hepatol 2014;61(4):957-61.

45. Pawlotsky J. Use and Interpretation of virological tests for hepatitis C. Hepatology 2002; 36:S65-S73.

46. Roerecke M, Rehm J. Cause-specific mortality risk in alcohol use disorder treatment patients: a systematic review and meta-analysis. Int J Epidemiol 2014;43(3):906-19.

47. Vogt M, Lang T, Frosner G, Klingler C, Sendl AF, Zeller A, et al. Prevalence and clinical outcome of hepatitis $\mathrm{C}$ infection in children who underwent cardiac surgery before the implementation of blood-donor screening. N Engl J Med 1999;341(12):866-70.

48. Kenny-Walsh E. Clinical outcomes after hepatitis $\mathrm{C}$ infection from contaminated anti-D immune globulin. $\mathrm{N}$ Engl J Med 1999;340(16):1228-33.

49. Seef LB, Miller RN, Rabkin CS, Buskell-Bales Z, Straley-Eason KD, Smoak BL, et al. 45-year follow-up of hepatitis C virus infection in healthy young adults. Ann Intern Med. 2000;132(2):105-111.

50. Wiese M, Berr F, Lafrenz M, Porst H, Oesen U. Low frequency of cirrhosis in a hepatitis C (genotype 1b) single-source outbreak in Germany: A 20-year multicentre study. Hepatology 2000;32(1):91-96.

51. Hansen AB, Gerstoft J, Kronborg G, Pedersen C, Sorensen TH, Obsel N. Mortality in siblings of patients coinfected with HIV and hepatitis C virus. J Infect Dis 2007;195(2):230-5.

52. Hansen AB, Lohse N, Gerstoft J, Kronborg G, Laursen A, Pedersen C, et al. Cause-specific excess mortality in siblings of patients co-infected with HIV and hepatitis C virus. PLoS One 2007;2(8):e738.

53. Dieperink E, Fuller B, Isenhart C, et al. Efficacy of motivational enhancement therapy on alcohol use disorders in patients with chronic hepatitis C: a randomized controlled trial. Addiction 2014;109(11):1869-77. 


\section{FIGURE LEGENDS}

FIG.1: Fraction of liver death attributable to chronic hepatitis C (CHC) according to age at death, in Denmark and Scotland. As a guide to interpretation, a total attributable fraction (TAF) of 0.00 would represent not attributable to CHC at all; a TAF of 0.50 would represent attributable to CHC and not attributable to CHC in equal parts; and a TAF of 1.00 would represent entirely attributable to CHC. 